\title{
Challenges for Implementation of Cross-Disciplinary Research in the Big Data Era
}

\author{
Merrill Series on \\ The Research Mission of Public Universities
}

A compilation of papers originally presented at a retreat sponsored by The Merrill Advanced Studies Center

July 2019

\author{
Mabel L. Rice, Editor \\ Technical editor: Suzanne Scales
}

MASC Report No. 123

The University of Kansas

(C) 2019 The University of Kansas Merrill Advanced

Studies Center or individual author 


\section{TABLE OF CONTENTS}

MASC Report No. 123

\section{Introduction}

Mabel L. Rice.

Director, Merrill Advanced Studies Center, the University of Kansas

Executive summary vii

\section{Keynote address}

Daniel Reed

Senior Vice President for Academic Affairs, the University of Utah

Big Data: Big Challenges, Big Opportunities

The Reification of Consilience

Robert Simari

University of Kansas Medical Center

Growing Diversity in Data Science: Shared Lessons from Clinical Trials

Lisa Federer 10

National Library of Medicine/National Institutes of Health

Quantifying Biomedical Data Reuse in an Open Science Ecosystem

Marianne Reed

University of Kansas

Journal Programs and Cross-Disciplinary Research

Daniel Sui and Jim Coleman

University of Arkansas

Convergence Research in the Age of Big Data: Team Science, Institutional Strategies, and Beyond

Dan Andresen and Eugene Vasserman 36

Kansas State University

Making Mountains out of Molehills: Challenges for Implementation of Cross-Disciplinary Research in the Big Data Era

Jennifer Clarke and Bob Wilhelm

University of Nebraska

Training for Cross-Disciplinary Research and Science as a Team Sport

Carl Lejuez

University of Kansas

Protecting the Value of Interdisciplinary Collaborations in the Development of a New Budget Model 
Christophe Royon, Tommaso Isidori and Nicola Minafra .....................54 University of Kansas

Cross-Disciplinary Research: From Nuclear Physics to Cosmic Ray Detection and Medical Applications

Jennifer Larsen and W. Scott Campbell ....................................................61

University of Nebraska Medical Center

Complexities of Conducting Cross-Disciplinary Biomedical Research

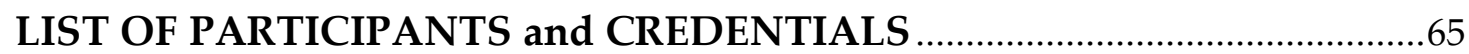

